\title{
A comparative study of proton transport properties of metal (IV) tungstates and their organic derivatives
}

\author{
HEEMANSHU PATEL, ALPANA PARIKH and UMA CHUDASAMA* \\ Department of Applied Chemistry, Faculty of Technology and Engineering, \\ MS University of Baroda, Vadodara 390 001, India
}

MS received 9 March 2004; revised 7 February 2005

\begin{abstract}
New hybrid inorgano-organic materials were synthesized by anchoring organic moieties, ortho chlorophenol and para chlorophenol onto metal (IV) tungstates viz. tin tungstate (SnW), titanium tungstate (TiW) and zirconium tungstate $(\mathrm{ZW})$ to give SnWoCP, SnWpCP, TiWoCP, TiWpCP, ZWoCP and ZWpCP, respectively. The materials were characterized for elemental analysis, thermal analysis (TGA, DSC), X-ray analysis and FTIR spectroscopy. Chemical resistivity of these materials were assessed in several acidic, basic and organic media. Further, the study of transport properties of these materials has been explored by measuring proton conductivity at different temperatures in the range $30-175^{\circ} \mathrm{C}$ using $\mathrm{HP4192A}$ impedance analyser over a frequency range $5 \mathrm{~Hz}-13 \mathrm{MHz}$ at a signal level below $1 \mathrm{~V}$. Based on the specific conductance data and Arrhenius plots, a suitable mechanism was proposed and conductance performance of derivatized and nonderivatized materials compared.
\end{abstract}

Keywords. Proton conductors; proton transport properties; solid electrolytes; ionic conductors; proton conduction in metal (IV) tungstates; proton conduction in derivatized metal (IV) tungstates.

\section{Introduction}

There is currently high interest in engineering mixed materials (organic/inorganic), where features of the organic and inorganic components complement each other leading to the formation of new solid-state structures and materials with new composite properties. Some examples of recent interest are inorganic solids with organic intercalates (Casciola et al 1989, 1993, 1994; Averill and Bringley 1990; Jones et al 1993), zeolites and open framework host materials with organic guests (Ozin 1992) and thin film heterostructures builtup from alternating layers of organic polyelectrolytes and colloidal inorganic polyanions (Keller et al 1994; Kleinfield and Ferguson 1994). New inorganic lattice structures are formed, resulting from cooperative interactions between the organic and inorganic components. In all cases, there is promise of developing new materials with properties not seen in purely organic or purely inorganic solids. Hybrid inorganoorganic compounds are novel multifunctional materials that offer a wide range of interesting properties. In this area, organic derivatives of inorganic ion exchangers of the class of tetravalent metal acid (TMA) salts are of particular interest. TMA salts have the general formula, $\mathrm{M}(\mathrm{IV})\left(\mathrm{HXO}_{4}\right)_{2} \cdot n \mathrm{H}_{2} \mathrm{O}$, where $\mathrm{M}(\mathrm{IV})=\mathrm{Zr}, \mathrm{Ti}, \mathrm{Ce}, \mathrm{Th}, \mathrm{Sn}$ etc and $\mathrm{X}=\mathrm{P}, \mathrm{Mo}, \mathrm{W}, \mathrm{As}, \mathrm{Sb}$ etc. The protons of the structural hydroxyl groups in these materials can be exchanged for several cations and thus they act as cation

*Author for correspondence (uvc50@yahoo.com) exchangers. They behave as protonic conductors due to the presence of surface hydroxyl protons that can easily move on the surface, accounting for their conductivities, which depend strongly on relative humidity, surface area and degree of crystallinity (Clearfield and Berman 1981).

Protonic conductors are often considered to be electrolytes in which hydrogen is transported towards and evolved at the cathode during electrolysis. Protonic transport includes transport of proton $\left(\mathrm{H}^{+}\right)$and any assembly that carries protons $\left(\mathrm{OH}^{-}, \mathrm{H}_{2} \mathrm{O}, \mathrm{H}_{3} \mathrm{O}^{+}, \mathrm{NH}_{4}^{+}, \mathrm{HS}^{-}\right.$etc). The transport of protons $\left(\mathrm{H}^{+}\right)$between relatively stationary host anions is termed the 'Grotthus' or 'Free-proton' mechanism. Transport by any other species is termed as a 'Vehicle' mechanism. In solids, vehicle mechanisms are usually restricted to materials with open structures (channels, layers) to allow passage of the large ions and molecules, while the Grotthus mechanism requires close proximity of water molecules, which is firmly held but able to rotate. Compounds with less amount of water would be expected to conduct by vehicle mechanism in which a nucleophilic group such as $\mathrm{H}_{2} \mathrm{O}$ or $\mathrm{NH}_{3}$ acts as a carrier of proton.

Anchoring of organic molecules bearing ionogenic groups such as $-\mathrm{OH},-\mathrm{CO}_{2} \mathrm{H},-\mathrm{SO}_{3} \mathrm{H}$, etc onto TMA salts are reported (Alberti et al 1985). Protons in these materials can also be replaced by several cations. Such materials are termed as inorgano-organic ion exchangers or hybrid materials or derivatized TMA salts.

Organic derivatives of $\alpha$-zirconium phosphate was first prepared by Alberti and coworkers and are represented 
by the general formula, $\alpha-\mathrm{Zr}\left(\mathrm{O}_{3} \mathrm{PR}\right)_{2} \mathrm{~S}$, where $\mathrm{R}$ is an organic group and $\mathrm{S}$ an intercalated molecule when present. $\alpha$-Zirconium carboxy alkylphosphonates (Alberti et al 1991) and $\alpha$-zirconium alkyl sulphophenylphosphonates (Alberti et al 1992a,b) have been investigated for their proton conduction properties. Proton conduction in layered metal (IV) phosphonates was studied by Alberti and Casciola (1997). Other workers have also reported on the proton conduction behaviour of intercalcated TMA salts (Costantino et al 1992; Casciola et al 1995; Stein et al 1996; Jaimez et al 1997; Szistet et al 1997; Yaroslavtsev et al 1997; Zima et al 1998). From our laboratory, we have reported proton conduction behaviour in amorphous zirconium phosphomolybdate and its single salt counterparts, zirconium molybdate and zirconium phosphate (Beena and Chudasama 1996) as well as organic derivatives of zirconium molybdate (ortho chlorophenol and para chorophenol anchored onto it) (Pandit et al 1998). Proton transport properties of M(IV) tungstates have also been reported by us (Parikh and Chudasama 2003), where $\mathrm{M}(\mathrm{IV})=\mathrm{Sn}, \mathrm{Ti}, \mathrm{Zr}$.

In the present endeavour, amorphous tungstates of tetravalent tin, titanium and zirconium abbreviated as SnW, TiW and ZW, have been synthesized. Further, their organic derivatives have been synthesized by anchoring ortho chlorophenol and para chlorophenol onto them abbreviated as SnWoCP, SnWpCP, TiWoCP, TiWpCP, ZWoCP and ZWpCP, respectively. The materials have been characterized for elemental analysis, thermal analysis (TGA, DSC), FTIR spectroscopy and X-ray analysis. Chemical resistivity of these materials have been assessed in various acidic, basic and organic media. Ion exchange capacity of these materials have been determined and effect of heating on ion exchange capacity studied. Earlier, ZWoCP and ZWpCP were synthesized, characterized and their ion exchange behaviour studied by us (Pandit and Chudasama 2001). Further we report the transport properties of derivatized materials as mentioned above using HP4192A Impedance Analyser, over a frequency range of $5 \mathrm{~Hz}-13 \mathrm{MHz}$ at a signal level below $1 \mathrm{~V}$ in the temperature range $30-175^{\circ} \mathrm{C}$. Specific conductance has been determined and the values compared with non derivatized samples.

\section{Experimental}

\subsection{Preparation of inorgano-organic materials (SnWoCP,} SnWpCP, TiWoCP, TiWpCP, ZWoCP and ZWpCP)

All three materials, SnW, TiW and $\mathrm{ZW}$, were prepared as per the method described earlier (Parikh and Chudasama 2003). The anchoring of ortho chlorophenol and para chlorophenol onto $\mathrm{SnW}$, TiW and $\mathrm{ZW}$ was carried out by treating $1 \mathrm{~g}$ of the acid treated TMA salt SnW, TiW or ZW with $20 \mathrm{ml}$ of pure distilled chlorophenol and heated to reflux for $\sim 2 \mathrm{~h}$. The excess organic reagent was de- canted. The material was then washed several times with alcohol so as to remove any trace of adhering chlorophenol from the surface. The sample thus obtained was dried at room temperature.

\subsection{Instrumentation}

The samples were analysed for tin, titanium and zirconium gravimetrically as their oxides by cupferron method (Elving and Olson 1955). Tungsten was determined gravimetrically as barium tungstate (Vogel 1978). Thermogravimetric analysis of the samples was performed on a Shimadzu DT-30 thermal analyser at a heating rate of $10^{\circ} \mathrm{C} / \mathrm{min}$. DSC of the samples were performed on Mettler TA 4000 system at a heating rate of $20^{\circ} \mathrm{C} / \mathrm{min}$. FTIR spectra of the samples were performed using $\mathrm{KBr}$ wafer on a Bomem MB series with Epson Hi 80 printer/plotter. X-ray diffractogram $\left(2 \theta=5-90^{\circ}\right)$ was obtained on X-ray diffractometer (Rigaku Dmax-30) with $\mathrm{Cu}-\mathrm{K}_{\alpha}$ radiation and nickel filter. Chemical stability/resistivity of the synthesized materials was assessed in different acids like $\mathrm{HCl}, \mathrm{H}_{2} \mathrm{SO}_{4}, \mathrm{HNO}_{3}$, bases like $\mathrm{NaOH}$ and $\mathrm{KOH}$, organic solvents like ethyl alcohol, diethyl ether, acetic acid etc. The $\mathrm{Na}^{+}$ion exchange capacity (IEC) was determined as usual by the column method (Nabi and Rao 1981). Further, the effect of heating on ion exchange capacity was also studied by heating several $1 \mathrm{~g}$ portions of the exchangers for $2 \mathrm{~h}$ at various temperatures in a muffle furnace and determining the $\mathrm{Na}^{+}$exchange capacity by the column method at room temperature.

\subsection{Conductivity measurements}

The proton conductivity of the materials was measured using pellets of $14 \mathrm{~mm}$ diameter and 1.5-2 mm thickness with relative humidity of $\sim 80 \%$. The opposite sides of the pellets were coated with conducting silver paste to ensure good electrical contacts. Impedance was measured in the temperature range $30-175^{\circ} \mathrm{C}$ using HP4192A Impedance Analyser, over a frequency range of $5 \mathrm{~Hz}-13 \mathrm{MHz}$ at a signal level below $1 \mathrm{~V}$, interfaced to a minicomputer for data collection. In all cases, since the impedance plots of the materials consist of single depressed semicircle, the pellet conductivity was calculated by arc extrapolation to the real axis, taking into account the geometrical sizes of the pellets.

\section{Results and discussion}

\subsection{Characterization}

SnW and ZW were obtained as white hard granules, whereas TiW was obtained as yellow granules. The derivatization of the organic moieties, ortho chlorophenol and para chlorophenol, is indicated visually by the change in colour of the inorganic matrix. SnWoCP, SnWpCP, 
TiWoCP, TiWpCP, ZWoCP and ZWpCP were obtained as light yellow, light brown, cream, light brown, light yellow and dark yellow colours, respectively, resembling the colour of organic resins.

Based on the chemical and thermal analysis, SnW, TiW and $\mathrm{ZW}$ were formulated as $\mathrm{Sn}\left(\mathrm{WO}_{2}(\mathrm{OH})_{2}\right) \cdot 5 \mathrm{H}_{2} \mathrm{O}$, Ti$\left(\mathrm{WO}_{2}(\mathrm{OH})_{2}\right) \cdot 6 \mathrm{H}_{2} \mathrm{O}$ and $\mathrm{Zr}\left(\mathrm{WO}_{2}(\mathrm{OH})_{2}\right) \cdot 8 \mathrm{H}_{2} \mathrm{O}$ (Parikh and Chudasama 2003).

Chemical resistivity of the materials in different acids, bases and organic media has been presented in table 1 .

As all three tungstates show similar behaviour, the figures of ZW has been exhibited as a representative for all characterizations (thermal, FTIR, X-ray, impedance plots etc).

TGA of SnW, TiW and ZW (figure 1) indicates 13\%, $14 \%$ and $15 \%$ weight loss, respectively within the temperature range $100-180^{\circ} \mathrm{C}$ corresponding to the loss of water molecules, after which a gradual weight loss is observed till $600^{\circ} \mathrm{C}$. This may be due to the condensation of structural hydroxyl groups. TGA of derivatized materials (figure 2 ) shows $\sim 11 \%$ weight loss at a temperature of $\sim 60^{\circ} \mathrm{C}$ which could be attributed to the loss of adsorbed moisture and traces of solvents used for washing the derivatized material after the reflux period. A gradual decrease in weight occurs up to $500^{\circ} \mathrm{C}$ indicative of the dissociation and decomposition of the organic part from the inorganic support and to the condensation of structural hydroxyl groups. DSC of ZW (figure 3) shows only one endothermic peak at $131.9^{\circ} \mathrm{C}$, which is attributed to the presence of water. There is no peak up to $500^{\circ} \mathrm{C}$, which indicates that there is no phase change. DSC of derivatized materials (figure 4) shows only one endothermic peak in the temperature range $100-190^{\circ} \mathrm{C}$ which could be attributed to loss of adsorbed moisture and traces of solvents used for washing the derivatized material after the reflux period and the presence of water. There is no peak up to $500^{\circ} \mathrm{C}$, which indicates that there is no phase change.

The FTIR spectra of ZW (figure 5) shows broad bands in the region $\sim 3400 \mathrm{~cm}^{-1}$ attributed to asymmetric and symmetric hydroxo-OH and aquo-OH stretches. A sharp medium band at $1620 \mathrm{~cm}^{-1}$ is attributed to aquo $(\mathrm{H}-\mathrm{O}-\mathrm{H})$ bending. The FTIR spectra of derivatized materials confirm the presence of the organic moiety on the inorganic matrix. The FTIR spectra of derivatized materials, ZWoCP (figure 6), show broad bands in the $\sim 3400 \mathrm{~cm}^{-1}$ region attributed to $-\mathrm{OH}$ stretches. A sharp band at $\sim 1620 \mathrm{~cm}^{-1}$ is attributed to aquo $\mathrm{H}-\mathrm{O}-\mathrm{H}$ bending and $\mathrm{C}-\mathrm{C}$ in plane stretching. Bands in the $\sim 1500-1400 \mathrm{~cm}^{-1}$ region and very weak bands in the $1300-1200 \mathrm{~cm}^{-1}$ region are attributed to the in plane bending of $\mathrm{C}-\mathrm{H}$ bonds. A band at $1100 \mathrm{~cm}^{-1}$ may be attributed to the presence of o-disubstituted benzene moiety. Bands in the $900-600 \mathrm{~cm}^{-1}$ are attributed to the out of plane bending of the ring $\mathrm{C}-\mathrm{H}$ bonds (Silverstein et al 1991).

Derivatization in case of layered TMA salts occurs through intercalation whereas in non-layered materials, organic molecules get either sorbed or anchored onto the surface or get encapsulated within the pores of the inorganic matrix. So far as the nature of bonding of the organic moiety with the inorganic matrix is concerned, it could be either weak van der Waals forces, encapsulation, hydrogen bonding, covalent bonding or a strong ionic interaction, resulting into the localization of the attractive forces (Singh et al 1985; Khan and Singh 1987; Varshney et al 1993). Several groups have commented on the nature of interaction of the organic guests with the inorganic matrix. In case of layered TMA salts, the organic moieties interact with the inorganic matrix through van der Waals forces or hydrogen bonding as revealed by the IR and TGA data (Alberti et al 1979; Dines and Digiacomo 1981). Interaction of amino acids such as L-asparagine and L-alanine with crystalline TMA salt, zirconium phosphate, has been suggested to occur through an ion exchange reaction (Kijima et al 1981). The adsorption of organic molecules such as phosphamidon and carbofuran occurs through the localization of the attractive forces, between the surface protons of the inorganic matrix and the $-\mathrm{CO}$ and $-\mathrm{PO}$ groups of the organic molecules (Singh et al 1985; Khan and Singh 1987; Varshney et al 1993). Anchoring of organic molecules such as sodium salts of chromotropic acid (1,8-dihydroxynaphthelene-3,6-disulphonic acid) and tiron (1,2-dihydroxybenzene-3,5-disulphonic acid) have been investiga-

Table 1. Chemical resistivity of derivatized and nonderivatized TMA salts.

\begin{tabular}{|c|c|c|c|c|c|c|c|c|c|}
\hline Medium & SnW & TiW & ZW & SnWoCP & SnWpCP & TiWoCP & TiWpCP & ZWoCP & $\mathrm{ZWpCP}$ \\
\hline \multicolumn{10}{|l|}{ Acids } \\
\hline $\mathrm{H}_{2} \mathrm{SO}_{4}$ & $36 \mathrm{~N}$ & $36 \mathrm{~N}$ & $3 \mathrm{~N}$ & $18 \mathrm{~N}$ & $18 \mathrm{~N}$ & $18 \mathrm{~N}$ & $18 \mathrm{~N}$ & $18 \mathrm{~N}$ & $18 \mathrm{~N}$ \\
\hline $\mathrm{HCl}$ & $1 \mathrm{~N}$ & $11 \cdot 3 \mathrm{~N}$ & $3 \mathrm{~N}$ & $11 \cdot 3 \mathrm{~N}$ & $5 \mathrm{~N}$ & $11 \cdot 3 \mathrm{~N}$ & $11 \cdot 3 \mathrm{~N}$ & $11 \cdot 3 \mathrm{~N}$ & $5 \mathrm{~N}$ \\
\hline $\mathrm{HNO}_{3}$ & $14 \mathrm{~N}$ & $14 \mathrm{~N}$ & $2 \cdot 8 \mathrm{~N}$ & $14 \mathrm{~N}$ & $4 \mathrm{~N}$ & $14 \mathrm{~N}$ & $14 \mathrm{~N}$ & $14 \mathrm{~N}$ & $2 \mathrm{~N}$ \\
\hline \multicolumn{10}{|l|}{ Bases } \\
\hline $\mathrm{NaOH}$ & $0.5 \mathrm{M}$ & $0 \cdot 1 \mathrm{M}$ & $1 \mathrm{M}$ & $0.001 \mathrm{M}$ & $0 \cdot 001 \mathrm{M}$ & $0.001 \mathrm{M}$ & $0.001 \mathrm{M}$ & $0.001 \mathrm{M}$ & $0.001 \mathrm{M}$ \\
\hline $\mathrm{KOH}$ & $0.5 \mathrm{M}$ & $0 \cdot 1 \mathrm{M}$ & $1 \mathrm{M}$ & $0.001 \mathrm{M}$ & $0.001 \mathrm{M}$ & $0.001 \mathrm{M}$ & $0.001 \mathrm{M}$ & $0.001 \mathrm{M}$ & $0.001 \mathrm{M}$ \\
\hline
\end{tabular}


ted in our laboratory (Pandit and Chudasama 1996, 1998). These salts possessing $-\mathrm{OH}$ as well as $\mathrm{SO}_{3} \mathrm{Na}$ groups are attached by ion exchange.

In the present study, a band at $1050 \mathrm{~cm}^{-1}$ attributed to the presence of the aryl chloride group (in neat $o \mathrm{CP} / p \mathrm{CP}$ )

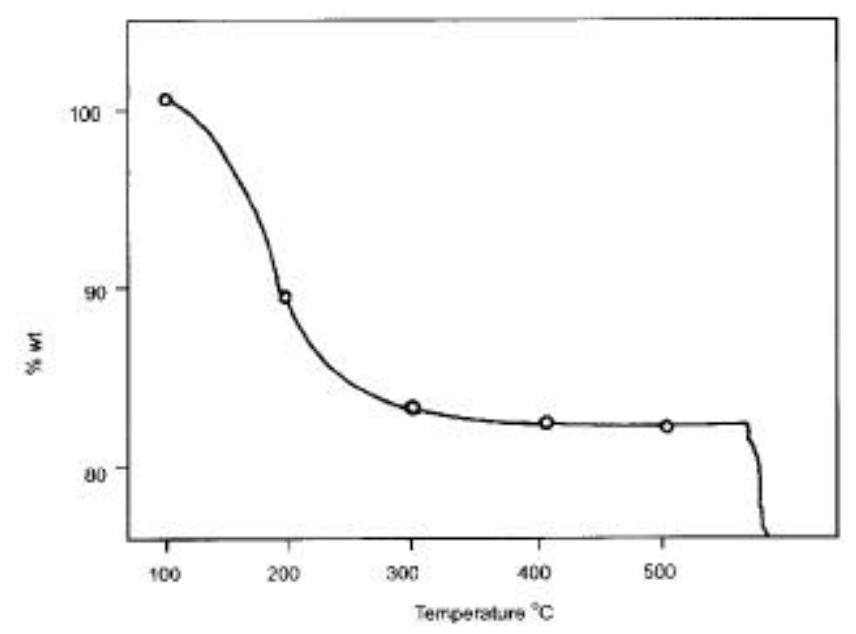

Figure 1. TGA plot for zirconium tungstate (ZW).

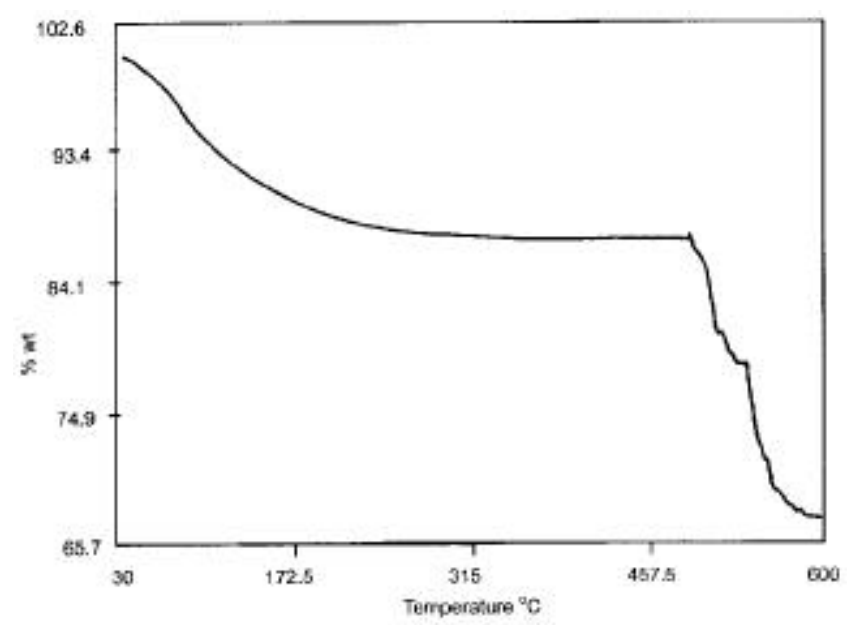

Figure 2. TGA plot for anchored material (ZWoCP).

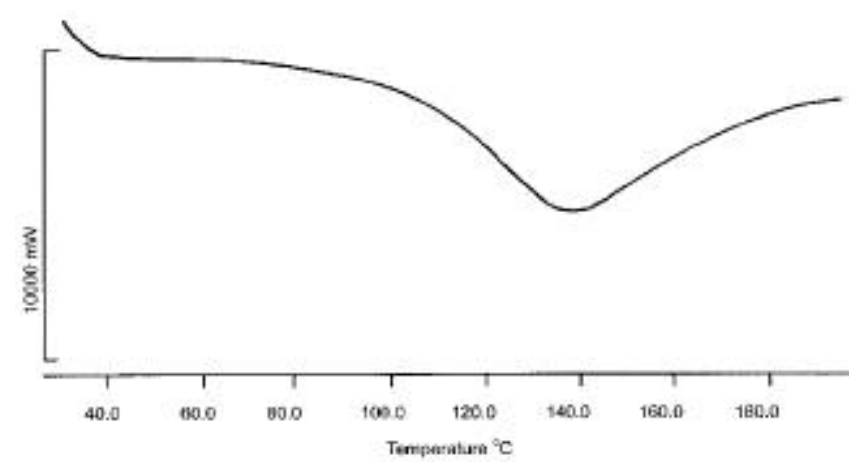

Figure 3. DSC curve for zirconium tungstate (ZW). however, disappears in the different FTIR spectrum of MWoCP-MW and MWpCP-MW ( $\mathrm{M}=\mathrm{Sn}, \mathrm{Ti}, \mathrm{Zr})$. The interaction could be proposed to occur through the $-\mathrm{OH}$ of the inorganic matrix and the $-\mathrm{Cl}$ of the chlorophenols, with the elimination of an $\mathrm{HCl}$ molecule (Pandit and Chudasama 2001).

The X-ray diffractograms of the materials do not show any sharp bands, indicating the materials to be amorphous in nature (figure 7).

The $\mathrm{Na}^{+}$exchange capacity of $\mathrm{SnW}, \mathrm{TiW}$ and $\mathrm{ZW}$ were found to be $1.52,1.95$ and $1.32 \mathrm{meq} \cdot \mathrm{g}^{-1}$, respectively whereas $\mathrm{Na}^{+}$exchange capacity of derivatized materials SnWoCP, SnWpCP, TiWoCP, TiWpCP, ZWoCP and $\mathrm{ZWpCP}$ were found to be $2 \cdot 64,2 \cdot 70,3.03,3.33,1.37$ and $1.46 \mathrm{meq} \cdot \mathrm{g}^{-1}$, respectively. The derivatized materials indicate an increase in IEC values as compared to that of nonderivatized materials. Also IEC of para derivatives is greater than ortho derivatives. The increase in IEC values is attributed to the presence of additional $\mathrm{H}^{+}$sites of the ionogenic $-\mathrm{OH}$ present in the organic moiety. However, the enhancement in the values of IEC is not large. This may be probably due to the fact that the amount of chlorophenol anchored is less. The lesser value of IEC for ortho derivatives as compared to para derivatives may be due to the steric hindrance felt by the exchanging ion in case of ortho derivatives as compared to the para derivatives.

The results of the effect of heating on IEC values represented in table 2 , reveals that in general IEC decreases

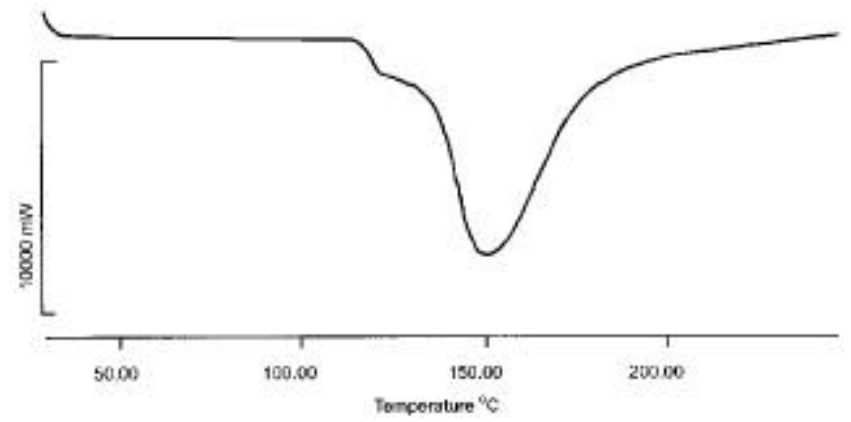

Figure 4. DSC curve for anchored material (ZWoCP).

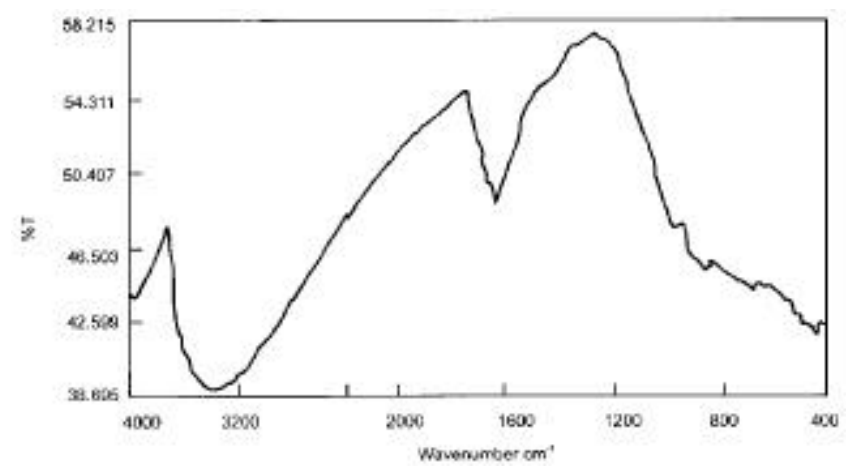

Figure 5. FTIR spectra of zirconium tungstate (ZW). 
on heating. This may be due to the condensation of structural hydroxyl groups at higher temperature. This fact is also evident from the FTIR spectra of the heated samples of ZW (figure 8). It is seen that the intensity of the peaks at $\sim 3400 \mathrm{~cm}^{-1}$ and $1620 \mathrm{~cm}^{-1}$ representative of the $-\mathrm{OH}$ group and external water molecules, respectively diminishes as heating temperature increases. However, in case of derivatized materials (table 3, figure 9), IEC initially decreases and exhibits a change in behaviour at temperatures between $200^{\circ} \mathrm{C}$ and $300^{\circ} \mathrm{C}$. In case of ortho derivatives, IEC decreases up to $200^{\circ} \mathrm{C}$ and then

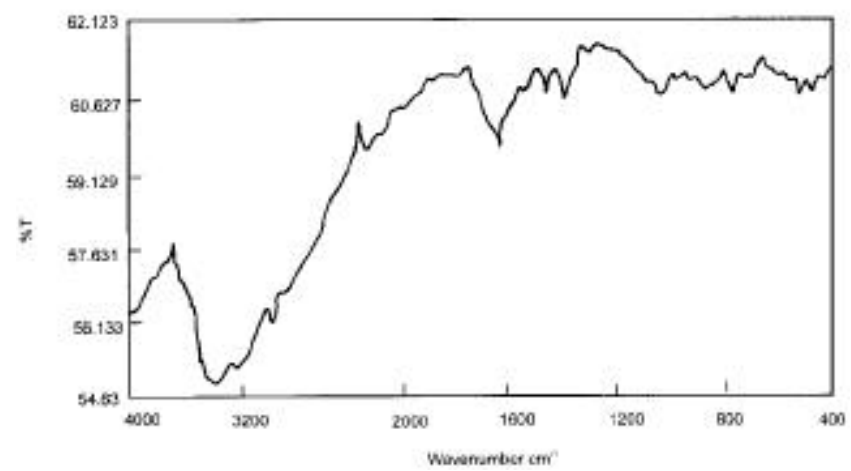

Figure 6. FTIR spectra of anchored material (ZWoCP). increases for the samples heated at $300^{\circ} \mathrm{C}$. Again for the samples heated at $400^{\circ} \mathrm{C}$ and $500^{\circ} \mathrm{C}$, IEC decreases. This may be due to the fact that, on heating in the range of 200 $300^{\circ} \mathrm{C}$, the organic moiety decomposes, leading to the formation of active carbon as evidenced by the change in colour of the heated samples, which is responsible for an increase in IEC that is later lost as $\mathrm{CO}_{2}$, as the temperature of heating increases. Similarly, in case of para derivatives, IEC values decrease on heating up to $200^{\circ} \mathrm{C}$ and then increase at $300^{\circ} \mathrm{C}$. Again at temperatures $400^{\circ} \mathrm{C}$ and $500^{\circ} \mathrm{C}$, the IEC value decreases. This study is supported by the FTIR spectra of the normal and heated samples. The intensities of the bands in the $\sim 3400 \mathrm{~cm}^{-1}$ region, between $1500-1400 \mathrm{~cm}^{-1}, 1250-1150 \mathrm{~cm}^{-1}$ and $1060-1010 \mathrm{~cm}^{-1}$ diminishes as the temperature of heating increases.

\subsection{Impedance measurements}

The results of specific conductance for nonderivatized (SnW, TiW, ZW) and derivatized materials (SnWoCP, SnWpCP, TiWoCP, TiWpCP, ZWoCP and ZWpCP) have been presented in table 4 . The complex impedance plots of $\mathrm{ZW}, \mathrm{ZWoCP}$ and $\mathrm{ZWpCP}$ at $30^{\circ} \mathrm{C}$ have been presented in figure 10 .

Table 2. Effect of heating on ion exchange capacity of SnW, TiW and ZW.

\begin{tabular}{|c|c|c|c|c|c|c|}
\hline \multirow[b]{2}{*}{ Temperature $\left({ }^{\circ} \mathrm{C}\right)$} & \multicolumn{3}{|c|}{ Colour } & \multicolumn{3}{|c|}{ Ion exchange capacity } \\
\hline & SnW & TiW & ZW & SnW & TiW & ZW \\
\hline Room temp. & White & Yellowish & White & 1.52 & 1.95 & $1 \cdot 32$ \\
\hline 100 & Yellowish & Yellowish & Yellowish & 1.08 & 1.90 & 0.49 \\
\hline 200 & Light brown & Yellowish & Light brown & $0 \cdot 82$ & $1 \cdot 28$ & $0 \cdot 24$ \\
\hline 300 & Brown & Dull green & Brown & $0 \cdot 62$ & $0 \cdot 72$ & $0 \cdot 22$ \\
\hline 400 & Brown & Dull green & White & $0 \cdot 50$ & $0 \cdot 26$ & $0 \cdot 16$ \\
\hline 500 & Brown & Dull green & White & $0 \cdot 39$ & $0 \cdot 21$ & $0 \cdot 10$ \\
\hline
\end{tabular}

Table 3. Effect of heating on ion exchange capacity of derivatized TMA salts.

\begin{tabular}{|c|c|c|c|c|c|c|c|c|c|c|c|c|}
\hline \multirow[b]{2}{*}{$\begin{array}{l}\text { Tempera- } \\
\text { ture }\left({ }^{\circ} \mathrm{C}\right)\end{array}$} & \multicolumn{6}{|c|}{ Colour } & \multicolumn{6}{|c|}{ Ion exchange capacity (meq $\cdot \mathrm{g}^{1}$ ) } \\
\hline & SnWoCP & SnWpCP & TiWoCP & TiWpCP & ZWoCP & $\mathrm{ZWpCP}$ & SnWoCP & SnWpCP & TiWoCP & TiWpCP & ZWoCP & $\mathrm{ZWpCP}$ \\
\hline $\begin{array}{l}\text { Room } \\
\text { temp. }\end{array}$ & $\begin{array}{l}\text { Light } \\
\text { yellow }\end{array}$ & $\begin{array}{l}\text { Light } \\
\text { brown }\end{array}$ & Cream & $\begin{array}{l}\text { Light } \\
\text { brown }\end{array}$ & $\begin{array}{l}\text { Light } \\
\text { yellow }\end{array}$ & $\begin{array}{l}\text { Dark } \\
\text { yellow }\end{array}$ & $2 \cdot 64$ & $2 \cdot 70$ & $3 \cdot 03$ & $3 \cdot 33$ & $1 \cdot 37$ & 1.46 \\
\hline 100 & $\begin{array}{l}\text { Light } \\
\text { yellow }\end{array}$ & $\begin{array}{l}\text { Light } \\
\text { brown }\end{array}$ & Cream & $\begin{array}{l}\text { Light } \\
\text { brown }\end{array}$ & $\begin{array}{l}\text { Light } \\
\text { yellow }\end{array}$ & $\begin{array}{l}\text { Dark } \\
\text { yellow }\end{array}$ & $2 \cdot 58$ & $2 \cdot 61$ & $2 \cdot 83$ & $3 \cdot 31$ & $1 \cdot 27$ & $1 \cdot 41$ \\
\hline 200 & Brown & $\begin{array}{l}\text { Dark } \\
\text { brown }\end{array}$ & Cream & Brown & $\begin{array}{l}\text { Dark } \\
\text { brown }\end{array}$ & Black & 1.95 & $2 \cdot 50$ & $2 \cdot 79$ & $3 \cdot 25$ & $0 \cdot 60$ & $1 \cdot 01$ \\
\hline 300 & Brown & $\begin{array}{l}\text { Dark } \\
\text { brown }\end{array}$ & $\begin{array}{l}\text { Light } \\
\text { brown }\end{array}$ & $\begin{array}{l}\text { Greenish } \\
\text { yellow }\end{array}$ & Black & Black & $2 \cdot 08$ & $2 \cdot 64$ & $3 \cdot 01$ & $3 \cdot 26$ & $0 \cdot 69$ & $1 \cdot 10$ \\
\hline 400 & Brown & Brown & $\begin{array}{l}\text { Greenish } \\
\text { yellow }\end{array}$ & $\begin{array}{l}\text { Greenish } \\
\text { yellow }\end{array}$ & Grey & Grey & 1.69 & $2 \cdot 62$ & $2 \cdot 16$ & $2 \cdot 48$ & $0 \cdot 18$ & $0 \cdot 34$ \\
\hline 500 & Brown & Brown & $\begin{array}{l}\text { Greenish } \\
\text { yellow }\end{array}$ & $\begin{array}{l}\text { Greenish } \\
\text { yellow }\end{array}$ & Grey & Grey & 1.58 & $2 \cdot 32$ & $0 \cdot 50$ & $1 \cdot 18$ & 0.08 & $0 \cdot 10$ \\
\hline
\end{tabular}


Table 4. Specific conductivity $\left(\Omega^{-1} \mathrm{~cm}^{-1}\right)$ for nonderivatized and derivatized TMA salts.

\begin{tabular}{|c|c|c|c|c|c|c|c|c|c|}
\hline Temp. $\left({ }^{\circ} \mathrm{C}\right)$ & SnW & SnWoCP & SnWpCP & TiW & TiWoCP & TiWpCP & ZW & ZWoCP & ZWpCP \\
\hline 30 & $2 \cdot 16 \times 10^{-4}$ & $3.44 \times 10^{-6}$ & $4.92 \times 10^{-6}$ & $1.29 \times 10^{-4}$ & $5.84 \times 10^{-8}$ & $1.10 \times 10^{-4}$ & $5.22 \times 10^{-5}$ & $1.63 \times 10^{-6}$ & $1.44 \times 10^{-5}$ \\
\hline 40 & $2.04 \times 10^{-4}$ & $3.22 \times 10^{-6}$ & $4.58 \times 10^{-6}$ & $1.03 \times 10^{-4}$ & $5.01 \times 10^{-8}$ & $1.01 \times 10^{-4}$ & $5.11 \times 10^{-5}$ & $1.57 \times 10^{-6}$ & $1.39 \times 10^{-5}$ \\
\hline 60 & $1.74 \times 10^{-4}$ & $3.02 \times 10^{-6}$ & $4.28 \times 10^{-6}$ & $7.02 \times 10^{-5}$ & $2.42 \times 10^{-8}$ & $6.01 \times 10^{-5}$ & $4.29 \times 10^{-5}$ & $1.22 \times 10^{-6}$ & $1.36 \times 10^{-5}$ \\
\hline 80 & $1.55 \times 10^{-4}$ & $2.77 \times 10^{-6}$ & $3.90 \times 10^{-6}$ & $5.41 \times 10^{-5}$ & $2 \cdot 19 \times 10^{-8}$ & $4.56 \times 10^{-5}$ & $3.12 \times 10^{-5}$ & $1.18 \times 10^{-6}$ & $1.27 \times 10^{-5}$ \\
\hline 100 & $1.43 \times 10^{-4}$ & $1.53 \times 10^{-6}$ & $2.60 \times 10^{-6}$ & $3.33 \times 10^{-5}$ & $1.67 \times 10^{-8}$ & $4.00 \times 10^{-5}$ & $2.55 \times 10^{-5}$ & $1.09 \times 10^{-6}$ & $1.19 \times 10^{-5}$ \\
\hline 120 & $1.11 \times 10^{-4}$ & $1.03 \times 10^{-6}$ & $1.39 \times 10^{-6}$ & $2.82 \times 10^{-5}$ & $1.15 \times 10^{-8}$ & $1.78 \times 10^{-5}$ & $2.50 \times 10^{-5}$ & $8.28 \times 10^{-7}$ & $1.01 \times 10^{-5}$ \\
\hline 140 & $1.02 \times 10^{-4}$ & $1.09 \times 10^{-7}$ & $1.57 \times 10^{-7}$ & $1.60 \times 10^{-5}$ & $1.04 \times 10^{-8}$ & $2.45 \times 10^{-6}$ & $5.22 \times 10^{-6}$ & $2.26 \times 10^{-7}$ & $2.07 \times 10^{-6}$ \\
\hline 160 & $2.04 \times 10^{-5}$ & $6.24 \times 10^{-7}$ & $1.20 \times 10^{-7}$ & $4.72 \times 10^{-6}$ & $8.88 \times 10^{-9}$ & $6.15 \times 10^{-7}$ & $1.87 \times 10^{-6}$ & $1.04 \times 10^{-7}$ & $6.30 \times 10^{-7}$ \\
\hline 175 & $4.30 \times 10^{-6}$ & $4.34 \times 10^{-7}$ & $8.63 \times 10^{-8}$ & $1.76 \times 10^{-6}$ & $8.25 \times 10^{-9}$ & $2.64 \times 10^{-7}$ & $3.69 \times 10^{-7}$ & $7 \cdot 10 \times 10^{-8}$ & $2.02 \times 10^{-7}$ \\
\hline$E_{\text {act }}(\mathrm{kcal} / \mathrm{mole})$ & 0.41 & $1 \cdot 00$ & 0.96 & 1.47 & $0 \cdot 76$ & $0 \cdot 72$ & 0.66 & $0 \cdot 37$ & 0.62 \\
\hline
\end{tabular}

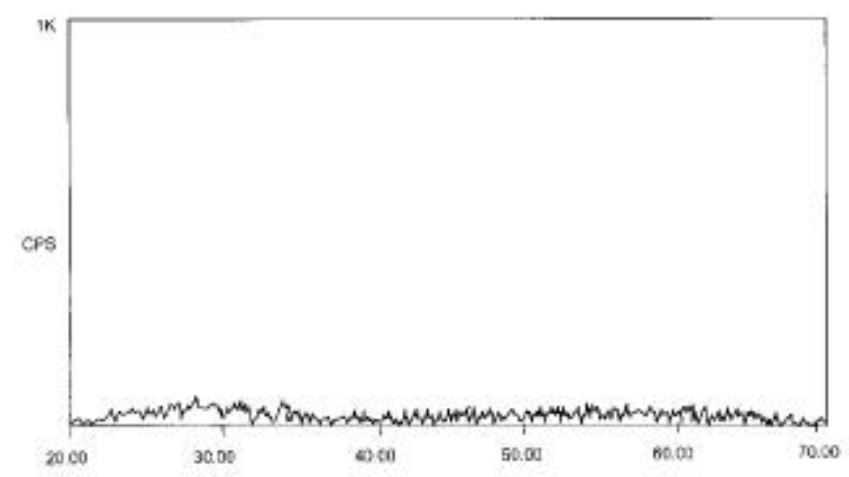

Figure 7. XRD pattern for zirconium tungstate (ZW).

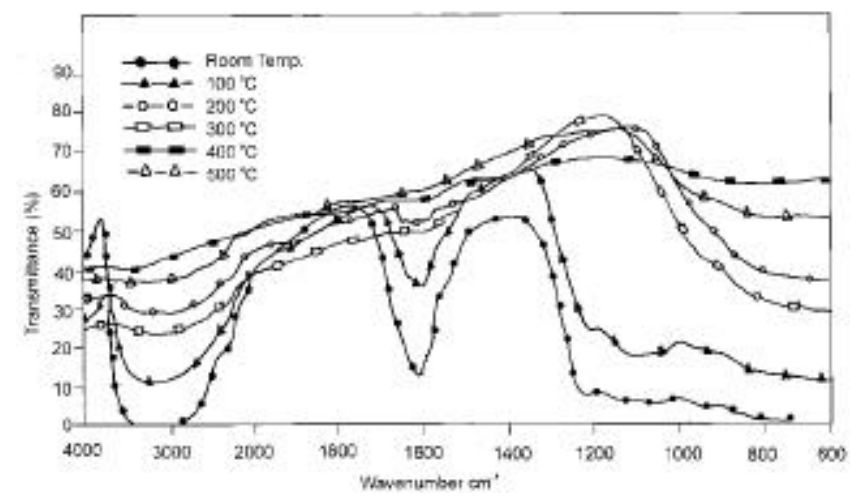

Figure 8. FTIR spectra of zirconium tungstate $(\mathrm{ZW})$ from room temperature to $500^{\circ} \mathrm{C}$.

For all the nine materials, it is observed that specific conductivity decreases with increasing temperature (table 4). This is attributed to the loss of water of hydration as well as the condensation of structural hydroxyl groups with increasing temperature. This fact is also supported by the study of effect of heating on IEC, that IEC decreases as the temperature of heating increases (also evident from the FTIR spectra of heated samples) (figures 8,9).

This suggests the mechanism of transportation to be of a Grotthus type (Clearfield 1988) where the conductivity depends on the ability of the water located on the surface

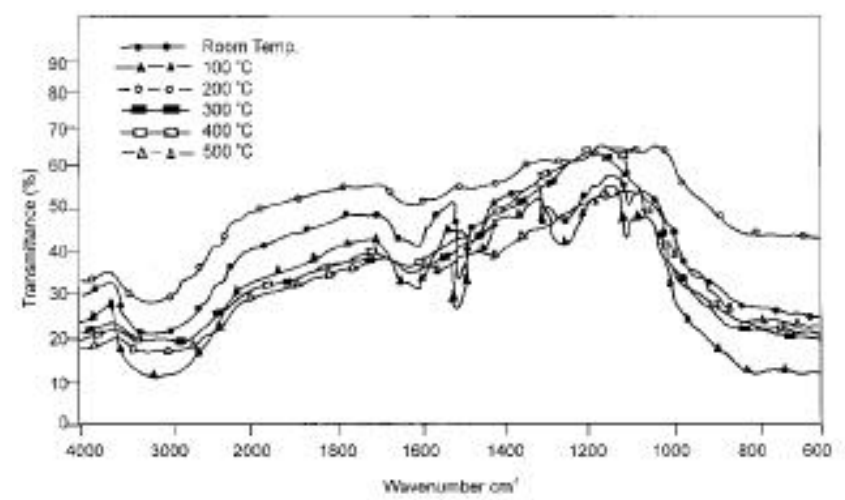

Figure 9. FTIR spectra of anchored material (ZWoCP) from room temperature to $500^{\circ} \mathrm{C}$.

to rotate and participate. Further, the results are also in agreement with the suggestion that protons are not able to diffuse along an anhydrous surface where the spacing of the $-\mathrm{OH}$ groups is too high (Alberti et al 1989). Besides, the fact that the loss of protons resulting from the hydroxyl condensation causes a considerable decrease in conductivity, indicates that the conduction is protonic also.

Arrhenius plots have been presented in figure 11 . For all materials, linearity was observed in the temperature range $30-120^{\circ} \mathrm{C}$. The energy of activation has been calculated and found to be (in Kcal/mole) $0.41(\mathrm{SnW}), 1.00$ (SnWoCP), 0.96 (SnWpCP), 1.47 (TiW), 0.76 (TiWoCP), 0.72 (TiWpCP), 0.66(ZW), 0.36 (ZWoCP) and 0.62 $(\mathrm{ZWpCP})$. From table 5 , it is observed that values of specific conductivity $(\sigma)$ at $30^{\circ} \mathrm{C}$ for all three tungstates exhibit the order $\mathrm{SnW}>\mathrm{TiW}>\mathrm{ZW}$. Further, specific conductivity values at $30^{\circ} \mathrm{C}$ for $\mathrm{SnW}$ and $\mathrm{TiW}$ is much higher than that of $\alpha-\mathrm{ZrP}\left(3.2 \times 10^{-6} \Omega^{-1} \mathrm{~cm}^{-1}\right)$ (Casciola and Bianchi 1985), but comparable to that of its modified forms like pellicular $\mathrm{ZrP}\left(1 \cdot 1 \times 10^{-4} \Omega^{-1} \mathrm{~cm}^{-1}\right)$ (Casciola and Costantino 1986). The values are also comparable to that of polymer electrolyte blends (Paulmer and Kulkarni 1992). In general, it is observed that specific conductivity of derivatized materials is less than that of nonderivatized materials. This can be explained on the basis of the fact that since the inorganic host $\mathrm{SnW}, \mathrm{TiW}$ and $\mathrm{ZW}$ are 
amorphous and nonlayered (Srivastava et al 1980), the organic guests get anchored on the surface of the inorganic matrix. Thus contribution due to internal protonic conduction is not possible as has been observed earlier (Casciola et al 1990). Further, as reported by Alberti et al (1978), in spite of the very high concentration of acid groups in layered materials, the bulk contribution to the conductivity is negligible because the main part of the measured conductivity is related to the surface. The very low bulk conductivity at room temperature could be due to lack of orientation and polarization of the $\mathrm{W}-\mathrm{OH}$ groups present in the materials. However, the observed
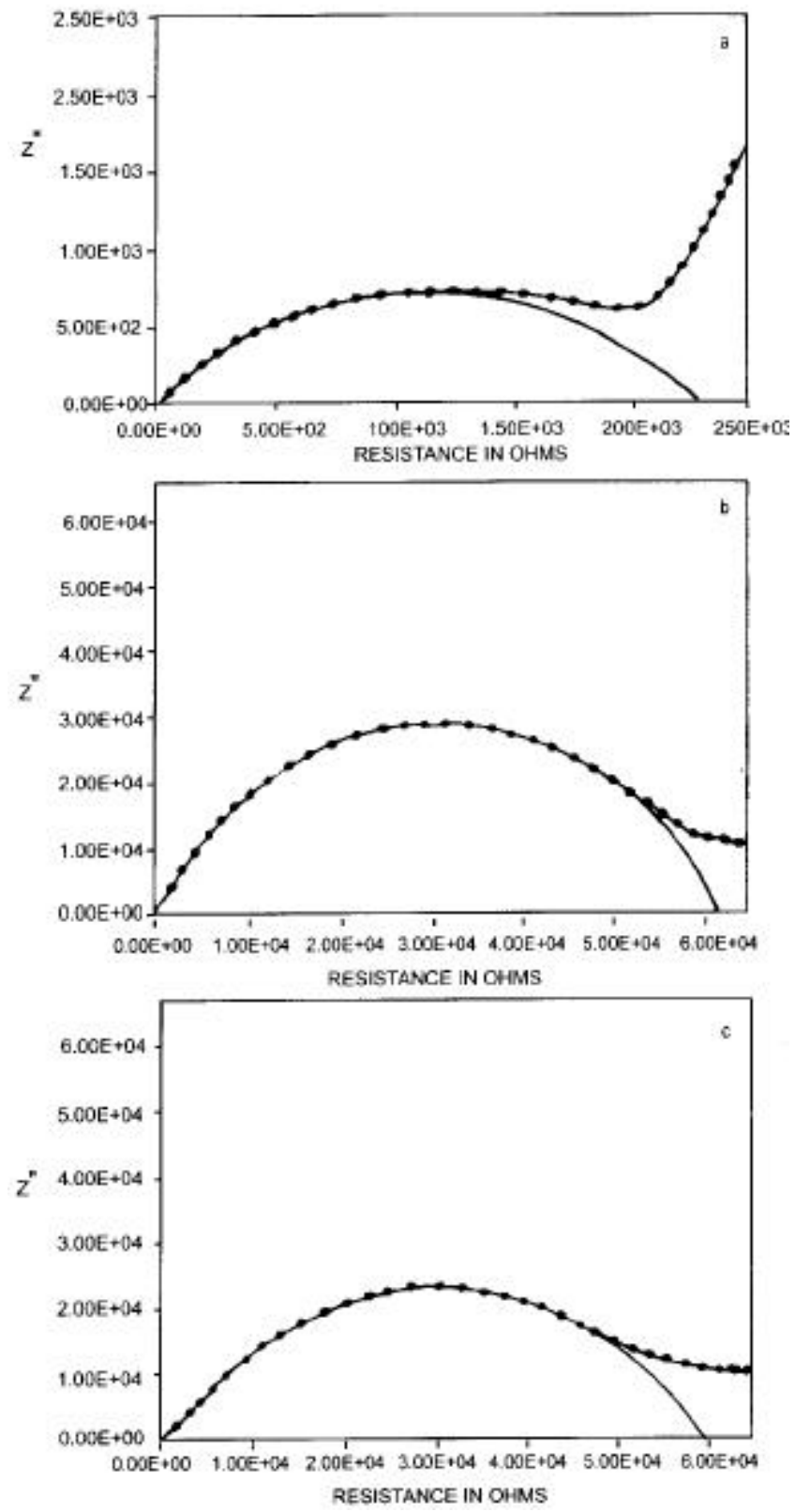

Figure 10. Complex impedance plots for a. zirconium tungstate $(\mathrm{ZW}), \mathbf{b}$. anchored material $(\mathrm{ZWoCP})$ and $\mathbf{c}$. anchored material (ZWpCP) conductivity is attributed to $\mathrm{W}-\mathrm{OH}$ groups present on the surface, which have freedom to rotate, as well as by the water molecules that are present (Casciola et al 1983).

Amongst the derivatized materials, specific conductivity values for ortho derivatives are less as compared to that of para derivatives. This could be attributed to their orientation on the matrix. In case of para chlorophenol
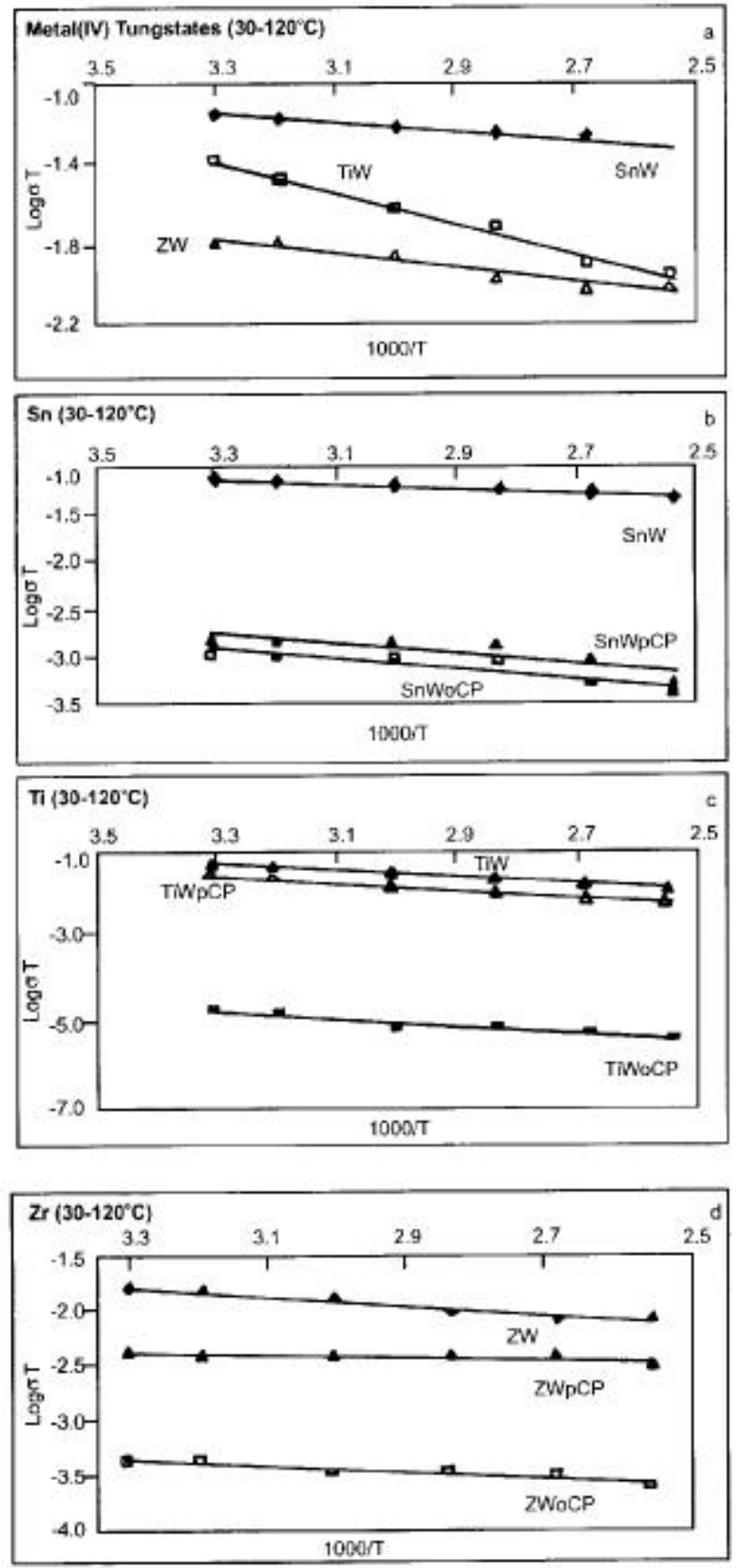

Figure 11. Arrhenius plots for a. metal (IV) tungstates, b. tin tungstate (SnW) and anchored materials (SnWoCp \& SnWpCP), c. titanium tungstate (TiW) and anchored materials (TiWoCP \& TiWpCP) and d. zirconium tungstate (ZW) and anchored materials $(\mathrm{ZWoCP} \& \mathrm{ZWpCP})$ in the range $30-120^{\circ} \mathrm{C}$. 
both orientation as well as the electron withdrawing nature of phenyl ring facilitates proton release for conduction.

\section{Conclusion}

The work reported in this paper is a humble attempt to establish the use of $\mathrm{SnW}$, TiW and ZW as well as their organic derivatives as proton conductors. However, further studies are being carried out in our laboratory to establish the various factors contributing to protonic conduction such as role of tetravalent metal, M(IV), and the anion e.g. phosphates, arsenates, molybdates, tungstates etc before making any final conclusions.

\section{Acknowledgements}

The authors gratefully acknowledge UGC, New Delhi, for financial assistance and the help rendered by Dr A R Kulkarni, IIT Bombay, in impedance measurements.

\section{References}

Alberti G and Casciola M 1997 Solid State Ionics 97177

Alberti G, Casciola M, Costantino U, Levi G and Riccardi G 1978 J. Inorg. Nucl. Chem. 40533

Alberti G, Costantino U and Giognavotti Luciani M L $1979 \mathrm{~J}$. Chromatogr. 18045

Alberti G, Costantino U, Koenyei J and Luciani M L 1985 React. Polym. 51

Alberti G, Costantino U and Palombari R 1989 First international conference on inorganic memb., Montpellier, France

Alberti G, Casciola M, Costantino U, Vivani R and Peraio A 1991 Solid State Ionics 4661

Alberti G, Casciola M, Costantino U, Peraio A and Montoneri E 1992a Solid State Ionics $\mathbf{5 0} 315$

Alberti G, Casciola M, Palombari R and Peraio A 1992b Solid State Ionics $\mathbf{5 8} 335$

Averill B A and Bringley J F 1990 Chem. Mater. 2180

Beena B and Chudasama U 1996 Bull. Mater. Sci. 19405

Casciola M and Bianchi D 1985 Solid State Ionics 17287

Casciola M and Costantino U 1986 Solid State Ionics 2069

Casciola M, Costantino U, Fazzini S and Tosaratti G 1983 Solid State Ionics $\mathbf{8} 27$

Casciola M, Costantino U and Marmottini F 1989 Solid State Ionics 3567

Casciola M, Chieli S and Costantino U 1990 Proc. of the fifth international conference on solid state protonic conductors (Assissi Società Chimica Italiana) p. B4

Casciola M, Costantino U and Calevi A 1993 Solid State Ionics 61245
Casciola M, Chieli S, Costantino U and Peraio A 1994 Solid State Ionics 4653

Casciola M, Costantino U, Peraio A and Rega T 1995 Solid State Ionics $\mathbf{7 7} 229$

Clearfield A 1988 Chem. Rev. 88125

Clearfield A and Berman J R 1981 J. Inorg. Nucl. Chem. 43 2141

Costantino U, Casciola M, Pani G, Jones D J and Roziere J 1992 Solid State Ionics 50315

Dines M B and Digiacomo P M 1981 Inorg. Chem. 2092

Elving Ph J and Olson E C 1955 Anal. Chem. 271817

Jaimez E, Hix G B and Slade R C T 1997 Solid State Ionics 97 195

Jones D J, Leloup J M, Ding Y and Roziere J 1993 Solid State Ionics 61117

Keller S W, Kim H N and Mallouk T E 1994 J. Am. Chem. Soc. 1168817

Khan A A and Singh R P 1987 Colloids and Surfaces 2433

Kijima T, Sekikawa Y and Ueno S 1981 J. Inorg. Nucl. Chem. 43849

Kleinfield E R and Ferguson G S 1994 Science 265370

Nabi S A and Rao R K 1981 J. Indian Chem. Soc. 111030

Ozin G A 1992 Adv. Mater. 4612

Pandit B and Chudasama U 1996 J. Chem. Res. (S) 484

Pandit B and Chudasama U 1998 Colloids and Surfaces A132 145

Pandit B and Chudasama U 2001 Bull. Mater. Sci. 24265

Pandit B, Beena B and Chudasama U 1998 Indian J. Engg. \& Mater. Sci. 577

Parikh A and Chudasama U 2003 Proc. Indian Acad. Sci. (Chem. Sci.) 1151

Paulmer R D A and Kulkarni A R 1992 Solid state ionics: Materials and applications (ed.) B V R Chowdari (Singapore: World Scientific) p. 549

Silverstein R M, Bassler G C and Morrill T C 1991 Spectrometric identification of organic compounds (New York: John Wiley and Sons) 5th ed, Ch. 3

Singh R P, Varshney K G and Rani S 1985 Ecotoxicol. Environ. Saf. 10309

Srivastava R K, Pal B, Raizada B B and Pandey K B $1980 \mathrm{~J}$. Indian Chem. Soc. LVII 391

Stein E W, Clearfield A and Subramanian M A 1996 Solid State Ionics $\mathbf{8 3} 113$

Szistet L, Szeleczky A M and Kuzmann E 1997 Solid State Ionics 97223

Varshney K G, Khan A A, Gupta U and Maheshwari S M 1993 Colloids and Surfaces 69265

Vogel A I 1978 Textbook of quantitative inorganic analysis (London: Longmans Green) 4th ed

Yaroslavtsev A B, Chuvaev V F and Sonntag R 1997 Solid State Ionics 97277

Zima V, Benes L and Melanova K 1998 Solid State Ionics 106 285 